\title{
Inventando a minha subjetividade de idosa: uma abordagem \\ complexa
}

\author{
Inventing my aged subjectivity: a complex approach
}

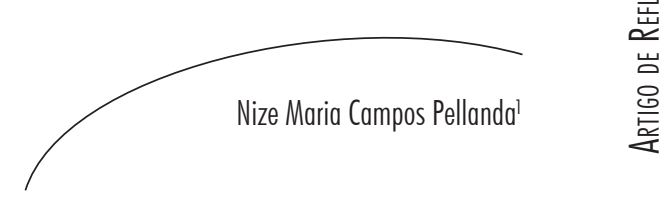

\section{Resumo}

$\mathrm{O}$ artigo trata de reflexões afetivo-cognitivas que emergiram a partir de pesquisas com cognição em uma abordagem complexa ao longo da vida da autora. Ela faz, então, um rápido histórico da modernidade em termos das pesadas consequências para a humanidade que isso acarreta ao criar fragmentações de todas as dimensões da realidade, o que implicaria sérios impedimentos para a construção de subjetividade/cognição. $\mathrm{Na}$ perspectiva da complexidade, há tentativas de ponta na ciência contemporânea que configuram um novo paradigma no sentido de adoção de uma lógica não-linear e não-determinista. Partindo destas considerações, a autora pensa a terceira idade como espaço para potencialização por meio de políticas para idosos mobilizadoras de autonomia, autoexperiência e autoria que possam proporcionar aos idosos reversão de entropia. Justifica a primeira pessoa em coerência com a posição epistemológica complexa adotada, ou seja, de não separar sujeito e objeto, dando conta das operações do próprio operador.

\section{Abstract}

The paper deals with affective-cognitive reflections that emerged from research on cognition in a complex approach throughout the life of the author. It is, then, a quick history of modernity in terms of the heavy consequences for humanity that entails creating fragmentations of all dimensions of reality, which would imply serious impediments to the construction of subjectivity / cognition. In view of the complexity, there are attempts in contemporary science that set a new paradigm in the sense of adopting a non-linear and non-deterministic logic. Based on these considerations, the author thinks the elderly as a space for empowerment through policies for seniors mobilizing autonomy, self-experience and authorship that can provide the elderly reversal of entropy. The author justifies the use of first person in line with the complex epistemological position adopted, ie not separating subject and object, giving an account of the operations of the operator.

Programa de Pós-graduação em Letras e em Educação, Departamento de Educação. Universidade de Santa Cruz do Sul. Santa Cruz do Sul, RS, Brasil.

Correspondência / Correspondence

Nize Maria Campos Pellanda

E-mail: nizepe@uol.com.br

Palavras-chave: Idoso. Cognição. Cibernética. Cibernética de segunda ordem. Complexidade. Terceira idade.
Key words: Aged. Cognition. Cybernetics. Second order cybernetics. Complexity. Old age. 
INTRODUÇ̧̃̃O

Nem todos podem estar na flor da idade, é claro! Mas cada um está na flor da sua idade.

Mario Quintana (do Caderno H)

Meu tema aqui é trazer algumas descobertas nas áreas da Biologia, da Cibernética e da Termodinâmica, entre outras, para refletir sobre a vida do idoso em termos de invenção de si e de reversão das condições entrópicas, tomando como referencial o paradigma da complexidade. Falar de qualquer tema nessa perspectiva é levar em conta o ponto de vista do observador. Por isso, resolvi assumir minha situação de idosa e falar de mim mesma para pensar as questões do idoso.

Como diria von Foerster, ${ }^{1}$ um dos referenciais mais importantes deste artigo: "De que mais se pode falar a não ser de si próprio?". Nesse caso, fica explicitada minha inserção no presente estudo: tenho 72 anos e, ao refletir sobre a vida dos idosos em termos das relações sujeito/ meio, relações consigo mesmo e processo de envelhecimento, reflito sobre mim mesma, sobre como tenho participado desse fluxo do viver inventando minha vida.

Uma mudança paradigmática está em processo de emergência. Uma lógica linear e simplificadora está sendo substituída por uma outra não-linear, circular e, portanto, complexa, que vai fazendo frente às consequências em termos de fragmentação da cultura moderna. A herança desta linearidade reducionista se expressa numa cultura de neurose, de depressão, onde as pessoas nesse processo de esfacelamento perderam a condição de pertencimento, perderam a capacidade de perceber que suas ações estão ligadas ao cosmos. Enfim, os seres humanos têm muita dificuldade de dar sentido a suas vidas. Como diria Bateson: perderam a noção do sagrado que esse cientista definia como nossa relação com o todo. ${ }^{2}$ Isso tudo, é claro, implica uma despotencialização de homens e mulheres.

Assim, no bojo desse tipo de cultura começa a emergir uma série de pesquisas que vão romper com as velhas práticas científicas. Dentre as pesquisas revolucionárias, vou usar como eixo teórico organizador deste texto a Teoria da Biologia do Conhecer, de Humberto Maturana e Francisco Varela. ${ }^{3}$ Vou focar minhas reflexões em torno do conceito central dessa teoria, o conceito de Autopoiesis e do mecanismo evolutivo por eles chamado de Acoplamento Estrutural. ${ }^{3}$

Autopoiesis refere-se ao processo fundamental do funcionamento da vida e foi pensado inicialmente por esses cientistas para explicar o mecanismo celular. Mais tarde, houve uma ampliação deste conceito na sua perspectiva rumo às questões de produção de si através da produção de diferença. $O$ conceito de acoplamento estrutural, por sua vez, é o mecanismo por meio do qual nos produzimos e sobrevivemos ao nos relacionar com o meio. Esse processo de produção inclui, de forma constituinte, o processo de cognição. Daí o nome da teoria Biologia do Conhecer ter sido escolhido por seus autores.

Ancorada nos dois pressupostos acima, como também em outras importantes descobertas do Movimento de Auto-Organização, tentarei mostrar como me apropriei desses elementos para construir cognição e a mim mesma ao mesmo tempo.

Em coerência com essas atitudes, vou buscar na Metodologia da Primeira Pessoa, de F. Varela ${ }^{4}$ e nos estudos de Cibernética de Segunda Ordem, de Heinz von Foerster, ${ }^{5}$ os instrumentos metodológicos para sustentar a arquitetura deste texto.

\section{COMPLEXIDADE E O MOVIMENTO DA AUTO- ORGANIZAÇÃO}

A partir dos finais do século XIX, começou uma série de rupturas epistemológicas com o paradigma newtoniano-cartesiano, pelo

\footnotetext{
* Movimento de Auto-Organização é um termo usado por Dupuy, JP, em seu livro "Nas origens das ciências cognitivas". (São Paulo: UNESP, 1996), para se referir às descobertas em diferentes áreas do conhecimento no século XX que usam o princípio da autoorganização em suas pesquisas. Os principais representantes foram os cibernéticos, na Biologia, Humberto Maturana, Francisco Varela e Henri Atlan, e Ilya Prigogine na Físioquímica.
} 
enfrentamento de situações complexas que desafiaram a ciência. Os cientistas já não poderiam mais responder de maneira linear, simplificadora e estática aos enfrentamentos com seus objetos. Esses fenômenos complexos passaram a apresentar principalmente características de instabilidades e tempo. A ciência clássica negava as questões do instável e do tempo. Assim, as teorias da evolução e as questões termodinâmicas apresentam-se como os arautos de um novo paradigma científico. Ao mesmo tempo, a geometria euclidiana começa a mostrar certas limitações e aparecem as equações não-lineares que abrem espaço para uma lógica não-aristotélica e circular. ${ }^{6}$

Já no começo do século XX, essa revolução científica se aprofunda significativamente com a Psicanálise e a Física Quântica. A primeira, ao trazer a questão do latente com o conceito de inconsciente, enfrenta o positivismo da ciência que somente admitia o patente/aparente. Isto abre caminho para a abordagem de temas sutis da vida humana que até então eram inconcebíveis. $\mathrm{Na}$ segunda, surge com muita força o papel do observador implicado no objeto observado. De certa forma, a Psicanálise também trouxe o problema do observador, com as preocupações de Freud sobre transferência e contra-transferência.

Ao longo do século, vão aparecendo estudos científicos e elaborações epistemológicas que aos poucos constituem um movimento impulsionado pelas questões sistêmicas e uma lógica circular que pudesse responder a esses novos desafios. As descobertas lógicas dos anos 1930, devido aos estudos de Alan Turing, entre outros, que resultaram na Máquina de Turing, vão dar subsídios para o desenvolvimento da cibernética alguns anos mais tarde. Trata-se de uma máquina do tipo universal que foca as dimensões lógicas do seu funcionamento, independentemente de sua implementação física.

Os resultados lógicos dessa experiência vão fazer emergir com muita força a questão da autoorganização, pois o que o funcionamento dessa máquina nos mostrou foi que aquilo que uma máquina pode fazer está muito além do mecânico. Nesse sentido, segundo Dupuy: "Se os teoremas de Turing nos mostram algo, é justamente que pensar não é necessariamente calcular."’

Começa a se configurar, com essas descobertas lógicas e outras da época, a tendência que passou a ser chamada de Movimento de Auto-Organização e que vai ter no movimento cibernético um importante reforço.

Nas décadas de 1940 e 1950, constitui-se o movimento cibernético que vai evoluir para a formatação de uma nova ciência, a Cibernética. Trata-se da primeira ciência efetivamente complexa, composta por diferentes áreas do conhecimento, entre as quais: Matemática, Epistemologia, Linguística, Antropologia, Neurobiologia, Inteligência artificial e outras. $\mathrm{O}$ movimento cibernético foi um dos movimentos científicos mais revolucionários da História da Ciência. Cientistas preocupados com as questões sistêmicas e focados nas preocupações de comunicação, controle e funcionamento da mente, reuniram-se sistematicamente ao longo de dez anos. Esses encontros foram conhecidos como as Conferências Macys em Nova York.

O ano de 1943 marca simbolicamente o início desse movimento, porque vieram a público artigos instigantes sobre princípios cibernéticos desencadeadores de discussões, que foram dando forma ao movimento a partir da preocupação em construir máquinas autorreguladoras. Essa primeira fase de estudos ainda desperta certa desconfiança do behaviorismo, devido à preocupação com entradas (inputs) e saídas (outputs). Mas, na verdade, já havia uma ruptura de fundo com o behaviorismo, pela presença dos mecanismos recursivos (feedback), já evidenciando uma lógica circular e um trabalho interno no sistema, o que é muito diferente da posição referida. O que reforça essa ideia de rompimento é a busca, por parte dos ciberneticistas, de padrões de comunicação, de relações circulares em rede e de laços fechados e, mais tarde, uma evolução para a concepção de sistemas que se abrem em espirais. Essa etapa inicial é conhecida como a Primeira Cibernética.

A chegada de Heinz von Foerster ao grupo, vindo da Áustria, assinalou a passagem para 
a Segunda Cibernética, o que impulsionou grandemente o movimento em termos de complexidade e aberturas para diferentes direções de pesquisa. Von Foerster não somente possibilitou ao movimento uma complexificação em direção a aberturas no sistema, como também, através da elaboração de importantes princípios, construiu as condições para a Biocibernética, abrindo caminho para os estudos de Maturana \& Varela e para a aprendizagem pelo ruído de Henri Atlan. ${ }^{8}$. As relações entre seres vivos e seu ambiente vão ter nas perturbações (ruído) um instrumento importante disparador de organização interna, inviabilizando que esses seres sejam determinados por essas perturbações. Os sistemas vivos, portanto, são autônomos e produtores de sua própria informação a partir das perturbações externas. Nesse sentido, não haveria possibilidade de informações externas elas são sempre produzidas internamente.

No que diz respeito ao ruído como disparador de processos organizadores, a contribuição de Prigogine, ${ }^{9}$ através dos estudos termodinâmicos de flutuações e bifurcações, foi muito significativa porque trouxe a questão da indeterminação e do devir na ciência.

A Cibernética foi uma das ciências mais importantes do Movimento da Autoorganização, tendo-se desdobrado em muitas direções diferentes mas o que nos interessa mais particularmente aqui é a questão dos fundamentos biológicos do conhecer e as implicações de tudo isso para a vida dos idosos.

Von Foerster, ${ }^{5}$ na sequência de suas contribuições à Segunda Cibernética, fará uma distinção entre "máquinas triviais" e "máquinas não-triviais", para deixar bem claro o rompimento das segundas com o behaviorismo, o caso das primeiras. As máquinas triviais trabalham como regras fixas em termos do princípio do estímulo-resposta. As máquinas não-triviais, pelo contrário, são aquelas que possuem um dinâmico estado interno capaz de se automodificar de acordo com as perturbações de forma não-previsivel, apresentando novidades.
Essas elaborações permitiriam mais tarde a von Foerster fazer ampliações de seu sistema de pensamento, para pensar a educação e também a terapia. Parece haver certa trivialização do idoso em termos de que ele está em fase de perda de autonomia e poucas condições se dão para que ele consiga ser autor de sua vida, ignorando-se assim a potencialidade que os seres humanos têm, em qualquer etapa de sua vida, de produzir seu processo de viver. Essa trivialização não é inócua porque diz respeito biologicamente a aspectos constituintes do humano, como a questão de formular problemas como um mecanismo de autoconstituição e automobilização.

Von Foerster ${ }^{5}$ fala de um ponto de vista cibernético, e os seres vivos são cibernéticos na medida em que se autorregulam. Por isso, podemos dizer que a cultura que cerca os idosos no mundo ocidental é uma cultura de trivialização. Para explicar melhor o uso do termo trivialização, emprestado de von Foerster, cito as próprias palavras do autor ao se referir ao sistema educacional em geral:

Estou usando o termo "trivialização" tal como se
usa na teoria dos autômatos, na qual uma máquina
trivial, se caracteriza por ter uma relação fixa entrada-
saída (input/output), enquanto que em uma máquina
não- trivial (máquina de Turing) a saída (output) está
determinada pela entrada (input) e pelo seu estado
interno. Considerando-se que nosso sistema educativo
está orientado para gerar cidadãos prediziveis, seu
objetivo é eliminar os estados internos perturbadores
que gerem imprevisibilidade e novidade. (p.184/185)

Uma cultura não-trivial seria aquela que mobilizaria os idosos no sentido de apostar em sua capacidade de autonomia e autoadministração. Ou seja, é preciso que aconteça um trabalho interno do sistema para que o idoso possa construir sentido para sua vida, realizando sua autopoiesis. Com isso, ele estaria revertendo entropia e melhorando sua qualidade de vida, pois aumentaria o trabalho interno do sistema através de conexões internas e externas.

$\mathrm{Na}$ esteira dos estudos de von Foerster, Humberto Maturana e Francisco Varela vão 
desenvolver a Teoria da Biologia do Conhecer, na qual eles definem os seres vivos como sistemas que se autoproduzem e que são fechados para a informação, mas, ao mesmo tempo, abertos para a energia. Isso revoluciona as concepções do vivo e coloca questões epistemológicas de fundo, na medida em que o sistema nervoso é considerado uma rede fechada com um funcionamento tal que ficam impossibilitadas afirmações sobre um mundo objetivo e independente do observador. O papel do observador aqui é fundamental, como já havia anunciado von Foerster com a Segunda Cibernética.

O conceito de Autopoiesis é o conceito-chave dessa teoria. A palavra foi cunhada a partir dos vocábulos gregos "auto" (por si) e "poiesis" (produção). A intenção era, pois, expressar a ideia de que os seres vivos produzem a si próprios através de mecanismos autorreguladores de um sistema fechado. Esse conceito será fundamental para podermos compreender as questões implicadas neste texto.

Ilya Prigogine, ${ }^{10}$ trabalhando naFísica/Química com suas pesquisas na área da Termodinâmica, vai aplicar o princípio da auto-organização exercendo então papel importantíssimo no paradigma da complexidade, na medida em que faz a ponte entre as ciências da natureza e as humanidades. Com sua teoria das Estruturas Dissipativas, que ganhou o Prêmio Nobel em 1977, ao falar em sistemas em equilíbrio e sistemas longe do equilíbrio, vai abrir as possibilidades na ciência de aplicar-se o conceito de entropia ao funcionamento dos seres vivos. Prigogine faz uma releitura da II Lei da Termodinâmica do século XIX, segundo a qual tudo no universo tende à morte térmica, estando, portanto, sujeito a uma entropia constante. No entanto, para os sistemas longe do equilíbrio, como os sistemas vivos, por exemplo, graças à presença da auto-organização, há uma reversão de entropia. ${ }^{9}$ Os sistemas vivos, portanto, por serem autorreguladores, são "retardadores de entropia". ${ }^{5}$

O que nos interessa aqui é trazer esses pressupostos para podermos entender as necessidades dos idosos em termos de garantir a eles condições de autoria e funcionamento em rede, que colocariam em ação mecanismos de autorregulação (autonomia) como produtores de energia e, ao contrário, a negação disso teria implicações entrópicas. Clara Oliveira ${ }^{11}$ expressa muito bem essa situação com suas posições sobre o que é um organismo doente. Diz ela:

\section{Um organismo encontra-se doente quando não consegue controlar este processo autoprodutor homeostático face à diferença, à novidade e à perturbação. Quando aprende a fazê-lo, fica de novo saudável e tornou-se mais complexificado. (p.35)}

Um mecanismo fundamental do viver para Maturana \& Varela ${ }^{3}$ é o do acoplamento entre sujeito e meio, que eles chamam de acoplamento estrutural. Trata-se de um processo constituinte e recursivo dos seres humanos que funciona de forma integrada cognição/subjetividade. $\mathrm{Na}$ situação dos idosos, é muito importante pensar-se em como se realiza esse processo, para que sejam garantidas as condições de um acoplamento tal que possibilite um trabalho interno importante e adequado à sua vida. Parece que nossa cultura não está preocupada com essas questões e o que temos é um ambiente que não facilita o acoplamento dos sujeitos, por não oferecer elementos a partir dos quais os seres humanos possam selecionar elementos que façam sentido para sua ontogenia. ${ }^{12}$

No que diz respeito à dimensão rede dos idosos, temos que considerar que se trata de seres biológicos de terceira ordem e, por isso, sua constituição subjetiva e cognitiva não pode prescindir da dimensão comunitário-social. ${ }^{11} \mathrm{Ou}$ seja, os seres humanos são seres que vivem em comunidade que os constituem como seres de rede.

\section{"A VISÃO A PARTIR dE DENTRO" OU A METODOLOGIA DA PRIMEIRA PESSOA}

Todas essas reflexões anteriores serviram-me não somente para pensar políticas para idosos como, principalmente, dispararam em mim perturbações tais que têm redundado na minha própria complexificação. O medo de certas 
condições de velhice, das doenças degenerativas e outros foram ruídos desestabilizadores que acabaram por me levar a um trabalho interno de reorganização. Com isso, assumi uma atitude autopoiética de autoria, de sensação de que tinha a tarefa de construir minha própria realidade buscando práticas mais saudáveis e valorizando muito meu trabalho profissional e minha vida familiar. Passei a afirmar minha autoria do meu viver, atitude estética que me trouxe uma sensação de alegria e potência.

A grande virada epistemológica inaugurada pela Cibernética com o papel do observador no sistema foi mais tarde incorporada como um dos pressupostos mais importantes da Biologia do Conhecer. Nesse sentido, não podemos falar de realidades independentes do observador, uma vez que não existe uma realidade objetiva lá fora a ser representada dentro do sujeito que conhece. Meu desejo de conhecer as condições de vida do idoso e a reversão de certas condições negadoras de possibilidades a eles fez com que eu ressignificasse isso nos meus próprios termos, levando à reinvenção de minha própria vida e assumindo minha condição de observadora incluída no sistema observado.

Nesse meu propósito, posso afirmar aqui que, sob o ponto de vista metodológico, meu papel de pesquisadora e de objeto coincidem, o que é aceitável dentro de uma lógica complexa que não trabalha com o terceiro excluído mas o inclui. Dessa forma, o que fiz foi pegar a realidade de "uma visão de dentro",, ou por dentro.

Fui percebendo que não existe conhecimento abstrato mas que a atividade cognitiva é algo concreto que emerge com a própria experiência. Varela ${ }^{4}$ fornece os elementos para sustentarmos uma tal metodologia através do uso da atenção, concebida aqui não como captação de algo externo mas no sentido atenção/presença do aqui e agora da observação de si próprio. Pensar sobre os próprios pensamentos é uma operação de segunda ordem ou metacognitiva que foi evidenciada com os estudos da Segunda Cibernética. ${ }^{13}$

\section{"A VIDA COMO OBRA DE ARTE" OU COMO INVENTEI MINHA SUBJETIVIDADE DE IDOSA}

Tentando entender os fundamentos biológicos do viver e a necessidade de pensarmos as questões dos idosos à luz das novas descobertas científicas, acabei por me repensar, e os instrumentos teóricos que construía ao estudar tornaram-se instrumentos de minha transformação subjetiva. E assim, impulsionada pelas práticas da ioga, que exerço com regularidade há mais de 30 anos, e pelos pressupostos divulgados por Paramanhansa Yogananda,${ }^{14} \mathrm{um}$ dos primeiros iogues a chegar ao Ocidente e divulgar a filosofia oriental, vou em frente em busca de minha autoconstrução, que é inseparável do meu processo de fazer ciência.

As ideias de "Seja mestre de si mesmo" e "Procure ser o capitão de seu próprio barco", expressas por Yogananda como a essência do pensamento iogue, me levam imediatamente a fazer pontes entre a sabedoria oriental e os novos pressupostos complexos..$^{14}$ Vou tecendo os pressupostos de autonomia/autoria numa rede que vai configurando aquilo que hoje estou sendo. Encontro incríveis analogias entre os iogues e o conceito de Autopoiesis. Percebo que, quanto mais pratico minha autoria (autonarrativas ou qualquer atitude de autoafirmação) mais inteira me sinto e, ao mesmo tempo, mais integrada com um todo maior.

Após um longo tempo praticando essas aproximações, fico absolutamente surpreendida quando ouço da própria boca do Maturana referência a Yogananda, por ocasião de um curso sobre "Raizes Biológicas da Existência Humana" no Instituto Matriztico de Santiago (2005). Os iogues, os budistas e outros representantes da cultura oriental enfatizam que ninguém pode se construir por nós e nos conduzir à iluminação. A autorrealização, que é o estado de consciência cósmica, só pode ser atingida pelo próprio sujeito que está envolvido profundamente num processo de tornar-se si mesmo.

Essas práticas e reflexões me levaram à elaboração de um projeto para entender 
mais profundamente a cognição em termos complexos, ou seja, numa inseparabilidade ser/ conhecer/fazer/falar. Acredito profundamente que nenhuma dimensão do ser humano possa ser separada. Ancorada nos pressupostos citados, como também nas pesquisas de Antonio Damásio, baseadas na unidade mente-corpo, ${ }^{15}$ parto para o processo de construção do conceito de ontoepistemogênese. ${ }^{16}$

O que tenho procurado mostrar nesse processo é que o sujeito em estado de autopoiesis elevada é capaz de aumentar seu nível de consciência e assim tomar posse de si mesmo. O que está implicado aí é um estado de intuição muito próxima à ideia de intuição como método de Bergson ${ }^{17}$ e, ainda, num outro nível os estados insightfullness que emergem com a meditação. ${ }^{13}$ A qualidade da cognição é profunda porque é um estado complexo, onde todas as dimensões do ser se juntam naquele momento, potencializando o sujeito que conhece e que vai fluindo no processo de ser.

Sobre a articulação da autopoiesis com a intuição bergsoniana no sentido de entender a cognição complexa, transcrevo as palavras de Maria do Céu Neves, na Introdução do livro de Bergson, Intuição Filosófica:

\section{[...] a intuição do eu, ao manifestar o dinamismo contínuo da consciência, fundamenta a existência inalienável da liberdade, enquanto capacidade que a consciência tem de, existindo, se criar indefinidamente a si mesma. ${ }^{18}(p .13)$}

Meu trabalho com o conceito de ontoepistemogênese, que venho construindo junto aos colegas de um grupo de pesquisa, refere-se às preocupações com a cognição como experiência vital e, por isso, um processo de fluxo de vida sempre em processo de complexificação crescente através das perturbações. Considero que o viver é um processo cognitivo e a cognição é sempre um processo de autoexperimentação que se dá em condições de perturbações constantes. Nesse sentido, afasto-me da Epistemologia Genética de Jean Piaget, ${ }^{19} \mathrm{em}$ direção às questões que dizem respeito à necessidade do ruído, de perturbações, flutuações e bifurcações.
A teoriapiagetiana trabalhacom os pressupostos de invariância das etapas, estabilizações e representações de um mundo exterior ao sujeito, o que evidencia a ideia de um mundo pré-dado e a previsibilidade de desenvolvimento, limitando assim o trabalho interno do sistema e simplificando o processo vital em termos de complexificação e produção de diferença. Em outras palavras, é a ordem a partir da ordem, o que é muito diferente da ordem a partir do ruído. ${ }^{5,8}$

$\mathrm{O}$ que isto tudo tem a ver, portanto, com o processo de envelhecer? $O$ envelhecer é um devir como qualquer outra etapa, mas nesta etapa do processo os ruídos são mais violentos e desestabilizadores, o que exige do idoso maior esforço de autorregulação e autoria. O fato de ter sido mobilizada por essas questões e ter achado um nicho (ontoepistemogênese) para construir minhas elaborações teóricas/eu mesma foi um verdadeiro processo de reinvenção que tem dado sentido à minha vida atual.

Neste sentido, escolho a vida que quero viver nesta etapa da minha vida. E o caminho escolhido, tenho bem claro em mim, não é fácil mas implica reversão de entropia a cada passo, com os problemas que emergem nesta fase do viver. Mas este é um trabalho de mobilização e de criação e, por isso, de complexificação. A serenidade que emerge de viver intensamente o momento presente de forma conectada é o prêmio de tudo isso.

\section{PERSPECTIVAS AUTOPOIÉTICAS PARA A VIDA DO IDOSO}

Com este trabalho e com o conjunto de meu processo de viver, não estou perguntando "o que são esses fenômenos complexos?" que estou estudando, nem tampouco "quem sou eu?". Mas as perguntas são dirigidas para "o que eu faço para chegar a conhecer tudo isso e ser o que sou?". Essa é a grande virada epistemológica defendida por Maturana. ${ }^{20}$ Isso tem implicações metodológicas em termos de uma passagem da substância para o processo. Foi por aí que 
pretendi andar. Portanto, eu sou o próprio processo dos meus atos.

Partindo dessas elaborações, proponho aos estudiosos que se debruçam sobre essas questões de forma transdisciplinar, a reflexão sistemática sobre as necessidades constituintes do idoso à luz dos pressupostos da Auto-Organização, no que diz respeito à produção de diferença (autoria), condições para enfrentamento das perturbações, considerações de questões termodinâmicas de reversão da entropia e potencialização das subjetividades. As questões de produção de sentido estão aí envolvidas profundamente, pois a cultura atual, de modo geral, não está preocupada com essa problemática, esquecendose que atividades como a literatura, por exemplo, ou a escrita de si ou de crônicas podem levar à simbolização, fator fundamental para a construção de sentido. Segundo Bosi, sentidos esses construídos também na relação com o outro, na experiência narrativa, no exercício da memória e na escuta e acolhimento da sociedade daquilo que é produzido individual e coletivamente pela subjetividade do idoso. ${ }^{21}$

Acredito que as possibilidades abertas pela Cibernética de segunda ordem que rompem com a ideia de uma realidade independente da atividade do sujeito cognitivo podem levar a melhores condições de vida para a humanidade. Para mim, essas descobertas de segunda ordem me ajudaram a entender dentro de mim mesma, os problemas fundamentais da vida do idoso e como se pode reverter isso produzindo energia através da produção de autoria e dos laços amorosos que estabelecemos com os outros.

\section{REFERÊNCIAS}

1. von Foerster H. Ethics and second-order cybernetics. Fredensborg: Universidade de Copenhague [acesso em 2011 mar 12]; Disponível em: www.fleck.kvl.dk/ cybernetics

2. Bateson G, Bateson, M.C. El temor de los ángeles. Barcelona: Gedisa; 2000.

3. Maturana H, Varela F. El árbol del conocimiento. Santiago: Universitária; 1990.

4. Varela F; Shear J.The view from within. Exeter UK: Short Run Press; 1999.

5. von Foerster H. Las semillas de la cibernetica. Obras escogidas. Barcelona: Gedisa; 1996.

6. Capra F. A teia da vida. São Paulo: Cultrix; 1996.

7. Dupuy J. Nas origens das Ciências Cognitivas. São Paulo: UNESP; 1996.

8. Atlan H. Entre o cristal e a fumaça. Rio de Janeiro: Zahar; 1992.

9. Prigogine I, Stengers I. Order out of chaos. Bantan: New York; 1984.

10. Prigogine I. From being to becoming. San Francisco: Freeman; 1980

11. Oliveira C. Auto-organização, educação e saúde. Coimbra: Ariadne; 2004.

12. Oliveira C. A educação como processo autoorganizativo. Lisboa: Instituto Piaget; 1999.

13. Varela F, Thompson E, Rosh E. The embodied mind. Cambridge: The MIT Press; 1991.

14. Yogananda P. The Divine Romance. Los Angeles: SRF; 2000.

15. Damasio A. Looking for Spinoza: joy sorrow and the feeling brain. Orlando: Harcourt, 2003.

16. Pellanda N.M.C. Construção de onto-epigênese na perspectiva da complexidade: um desafio para epistemólogos e educadores. In: Congresso da ANPED; Caxambú. Santa Cruz do Sul: Universidade de Santa Cruz do Sul: 2006. P1-17.

17. Bergson H. A intuição filosófica. Lisboa: Colibri; 1994.

18. Neves M.C. Introdução. A Intuição Filosófica. Lisboa: Colibri; 1994.

19. Piaget J. Epistemologia Genética. São Paulo: Abril; 1983.

20. Maturana H, Porksen B. Del ser al hacer. Santiago: J.C. Saez; 2004.

21. Bosi E. Cultura e desenraizamento. São Paulo, Ática, 1987. 